\title{
Re: Body Mass Index as a Predictor of Outcomes Among Pediatric Kidney Transplant Recipient
}

Dick AAS' ${ }^{1}$, Hansen $\mathrm{RN}^{2}$, Montenovo $\mathrm{MI}^{3}$, Healey $\mathrm{PJ}^{1}$, Smith $\mathrm{JM}^{4}$

'Seattle Children's Hospital, Clinic of Surgery, Section of Pediatric Transplantation, Seattle, USA

${ }^{2}$ University of Washington School of Pharmacy, Pharmaceutical Outcomes Research and Policy Program, Seattle, USA

${ }^{3}$ University of Washington, Department of Surgery, Division of Transplantation, Seattle, USA

${ }^{4}$ Seattle Children's Hospital, Clinic of Pediatrics, Division of Nephrology, Seattle, USA

Pediatr Transplant 2017. doi: 10.1111/petr.12992.

\section{EDITORIAL COMMENT}

In the adult population obesity is a serious problem for patients requiring kidney transplantation by causing delayed graft function (DGF) and deep wound infections which in the long run having a negative impact on graft and patient survival. However, there are controversial reports regarding the pediatric population. In this retrospective largest cohort study authors have examined the association between body mass index (BMI) and patient outcomes among 13014 primary pediatric kidney transplant recipients (<18 years old) between 1987 and 2013 from United Network for Organ Sharing database. After stratifying the patients into five categories according to their BMI based on their Z scores, which was established by World Health Organization. The majority of the patients (12588) was in the $Z$ score category of -2 to +2 and was used as the reference group. -3 (thin) and +3 (obese) categories were evaluated for differences in graft and patient survival. There was no difference in graft or patient survival and no differences in rates of DGF among obese children compared to normal and underweight children undergoing kidney transplantation. However, these results should be interpreted very carefully because of its retrospective nature and also reflection of just one nation. Childhood obesity is a serious problem with increasing prevalence and obese children with end stage kidney disease should not be eliminated from having a kidney.

Yarkın Kamil Yakupoğlu, MD

๑Copyright 2017 by the Association of Urological Surgery / Journal of Urological Surgery published by Galenos Publishing House. 